\title{
Quantifying environmental and financial benefits of using porters and cycle couriers for last-mile parcel delivery
}

McLeod, F.N. ${ }^{1}$, Cherrett, T.J. ${ }^{1}$, Bektas, T. ${ }^{2}$, Allen, J. ${ }^{3}$, Martinez-Sykora, A. ${ }^{1}$, LamasFernandez, C. ${ }^{1}$, Bates, O. ${ }^{4}$, Cheliotis, K. ${ }^{5}$, Friday, A. ${ }^{4}$, Piecyk, M. ${ }^{3}$, Wise, S. ${ }^{5}$

${ }^{1}$ University of Southampton, Highfield, Southampton, SO17 1BJ, UK (Email:

F.N.McLeod@soton.ac.uk (corresponding author))

${ }^{2}$ School of Management, University of Liverpool, UK.

${ }^{3}$ Faculty of Architecture and the Built Environment, University of Westminster, UK.

${ }^{4}$ School of Computing and Communications, Lancaster University, UK.

${ }^{5}$ Faculty of the Built Environment, University College London, UK.

\begin{abstract}
Parcel carriers face increasingly difficult operating conditions in busy metropolitan areas due to growing consumer demand for ever faster delivery services and having to cope with traffic congestion and city authority measures that may restrict or penalise access for certain types of vehicle. This paper evaluates the potential environmental and financial benefits of switching from traditional van-based deliveries to an alternative operating model, where porters or cycle couriers undertake deliveries supported by a substantially reduced van fleet.

Results using a specially-developed algorithm to model operations of a real carrier in an area of central London, $\mathrm{UK}$, suggested that the carrier could reduce $\mathrm{CO}_{2}$ emissions by $45 \%$, $\mathrm{NOx}$ emissions by $33 \%$, driving distance by $78 \%$ and curbside parking time by $45 \%$. Overall cost savings to the carrier were estimated to be in the range 34\%-39\%. Scaling up the modelled emissions savings to London's Central Activities Zone, an area of approximately $30 \mathrm{~km}^{2}$ and with current total annual parcel delivery distance of around 15 million $\mathrm{km}$, could see annual emissions savings in the region of 2 million $\mathrm{kg} \mathrm{CO}_{2}$ and $1633 \mathrm{~kg}$ NOx if all carriers utilised porters or cycle couriers. The key operating challenges identified were related to sorting and consolidating items by weight and volume, parcel handover arrangements and how to deal with express items and failed deliveries.
\end{abstract}

Keywords: parcel delivery; sustainable transport; last-mile logistics 


\section{Introduction}

The number of parcels delivered globally grew by $17 \%$ in 2018 , to 87 billion (Post and Parcel, 2019) with 3.7 billion being delivered in the UK alone (Mintel, 2019). With growing parcel volumes, there has been a commensurate increase in the demand for next-day, sameday and 'instant' (within two hour) delivery services (Dablanc et al, 2017). As a result, 'lastmile delivery' (transport from a local depot to the final delivery destination) is becoming increasingly challenging for parcel carriers, especially in busy cities with traffic congestion, shortage of available parking spaces and vehicle access restrictions. It can also be expensive, with FedEx and UPS incurring parking fines of 14.9 and 33.8 million US dollars respectively while serving consignees in New York City during 2018 (Baker, 2019). Such fines can be difficult to avoid in big cities where delivery density is high and van drivers spend significant amounts of time away from the van making deliveries on foot: for example, in central London it was observed that parcel delivery vans were parked by the curbside for around two-thirds of the time spent in the delivery area with the driver walking $10 \mathrm{~km}$ per day (Allen et al, 2018a).

In response to such issues, parcel carriers are investigating how integrated solutions using walking porters or cycle couriers alongside traditional vans may be used to reduce their operating costs and overall transport footprint (DHL, 2016). Using a case study involving a major parcel carrier undertaking primarily non-express parcel deliveries to individuals and businesses in central London, this paper sets out to quantify the environmental and financial benefits of using porters and cycle couriers for last-mile parcel delivery, proposing an operating model not seen in common practice, in which collection-and-delivery points (CDPs) such as general stores are used for transfer of parcels between van drivers and porters or cycle couriers. The research contributions made in the paper are: (i) an assessment of the relative costs and benefits of using porters or cycle couriers alongside van-based parcel 
delivery systems using a bespoke algorithm; ii) identifying the challenges that would need to be addressed in order to develop a successful operational and business case for such integrated last-mile delivery systems.

\subsection{The use of on-foot porters as a logistics mode}

Although postal services in dense urban areas are commonly undertaken on foot, sometimes aided by trollies, there are relatively few examples of porters being used as a specific lastmile delivery solution in the parcels industry. DHL set up a portering operation in New York's lower Manhattan financial district, where a 1200 square foot facility was used as a base for porters to serve the local area (DC Velocity, 2016; DHL, 2016), expanded in 2018 to the Midtown East district of New York with the opening of a second facility served by 22 porters (DHL, 2018). Results from a portering trial in central London, where pre-packed 200L bags of parcels were transferred at the roadside between drivers and porters, suggested reductions of up to $86 \%$ and $60 \%$ in vehicle parking and driving time respectively, realising savings in operating costs of between 14\%-24\% per parcel (Piecyk et al, 2019). Another follow-on trial suggested that one van driver and four porters could be used to deliver the same number of parcels as five van drivers (Ryan, 2019).

\subsection{The use of cycle couriers as a logistics mode}

Many countries have seen a growth in parcel delivery services using bikes or electricallyassisted cargo bikes (e-bikes) (Cyclelogistics, 2011) and cycle couriers are increasingly selfemployed individuals paid on a per-delivery basis (US Postal Service, 2014), allowing the last-mile delivery problem to be addressed through informal networks of people managed through internet-based platforms. This has led to an abundance of cycle couriers in many major cities with Deliveroo having over 15,000 registered riders in the UK alone (Business of Apps, 2019). With e-bikes now capable of transporting loads between $50-250 \mathrm{~kg}$ up to $80 \mathrm{~km}$ on a single charge (Schier et al, 2016), research has suggested that between $25 \%$ and $50 \%$ of 
current freight traffic destined for urban centres could be transferred from motorised vehicles to e-bikes using a dedicated cycle depot or micro-consolidation centre as a base (Melo and Baptista, 2017; Lenz and Riehle, 2013; Cyclelogistics, 2014; Schliwa et al, 2015; Wrighton and Reiter, 2016) and could benefit from the improved journey times that can result (Conway et al, 2012). Observations from 30 different cycle courier operators across Europe suggested a mean travel speed of 10mph (PRO-E-BIKE, 2015) which, in some cases, may outperform vans as, for example, in central London, where the average general traffic speed in 2018 was reported to be only 8mph (Mayor of London and Transport for London, 2018).

\subsection{The potential environmental and operational benefits of adopting sustainable last- mile modes}

The environmental benefits of moving to sustainable transport modes (e.g. walking and cycling) for last-mile parcel logistics can be considerable and several studies have estimated these. Electrically-assisted cargo cycles used in conjunction with a micro-consolidation centre in London, $\mathrm{UK}$ and Milan, Italy reduced the $\mathrm{CO}_{2}$ emissions per parcel delivered by $55 \%$ and $73 \%$ respectively compared to diesel vans (Browne et al, 2011; Nocerino et al, 2016). Pilot studies involving 78 e-bikes used by 40 companies or municipal authorities for various types of delivery in 20 cities across Croatia, Italy, Netherlands, Portugal, Slovenia, Spain and Sweden estimated emissions savings of up to $8.5 \mathrm{~kg} \mathrm{CO}_{2}$ per journey (PRO-EBIKE, 2015). Annual fuel savings of 8,500,000 litres and $\mathrm{CO}_{2}$ savings of 21,000 tonnes were estimated, based on cycle couriers gaining a $10 \%$ share of the urban delivery market from vans across the Netherlands (Maes and Vanelslander, 2012). $\mathrm{CO}_{2}$ savings of between $3 \%$ and $28 \%$, were estimated for a business model where delivery of light packages (up to $5 \mathrm{~kg}$ ) in Turin, Italy were undertaken by 'green subcontractors' using e-bikes with heavier items being delivered by 'traditional subcontractors', using diesel-fuelled vans (Perboli and Rosano, 2019). 
A significant operational benefit of using porters or cycle couriers is the reduction in time associated with parking. In Turin, Perboli and Rosano (2019) estimated that delivery times by van were between 4 and 5 minutes per consignee whereas, by cycle courier, they reduced to between 2 and 2.5 minutes. Similar results were found for parcel couriers in London, with an average delivery time of 3 minutes per consignee for porters and cycle couriers and 5 minutes for van drivers measured from GPS tracking surveys (Allen et al., 2018b).

\subsection{Approaches to manage integrated last-mile delivery modes}

In practice, companies that utilise sustainable last-mile delivery modes (e.g. Ecopostale (Belgium), Zedify (UK), Gnewt Cargo (UK)) often do so out of their own depot facilities and typically acting as a 'carrier's carrier', delivering items on behalf of major carriers who drop off parcels to them to reduce their transport footprint in dense city centres. The operating model proposed in this paper, first introduced by the authors in Allen et al (2018a), is quite distinct from this. Here, we consider multi-drop delivery tours for cycle couriers or porters who obtain parcel loads from manned or unmanned collection-and-delivery points (CDPs) such as general stores, post offices or locker banks. They replace the need for a dedicated depot facility for the last-mile courier company thus saving on infrastructure costs and allowing for flexibility in facility location. The CDPs are supplied with pre-sorted bags or boxes of parcels (see section 2.2.2) by a substantially reduced team of van drivers who may also retain some other tasks, depending on the carrier's work profile and preferences, such as:

(i) delivery of any items that are considered too heavy or bulky for the cycle courier or porter;

(ii) delivery of any high value or express items; (iii) customer collections.

Operationally, the parcel carrier may prefer to outsource the last-mile delivery task (to be undertaken by porters or cycle couriers) to crowdshippers (independent couriers) rather than employ and manage porters or couriers themselves, to avoid any associated difficulties (US Postal Service 2014, McKinnon, 2016). 


\section{Methodology}

A 'before-and-after' case study analysis was performed based on actual van delivery rounds undertaken by a major carrier during one week in an area of central London (Figure 1) compared with alternative portering and cycling scenarios modelled using a heuristic algorithm developed by the authors (section 2.5). All individual consignments weighing $5 \mathrm{~kg}$ or less were deemed to be suitable for a porter or cycle courier to deliver (Allen et al, 2018a; Perboli and Rosano, 2019), with drivers retaining the heavier consignments and undertaking collections, which made up fewer than $5 \%$ of the overall transactions. In practice, bulky items, irrespective of weight, may also be best handled by the driver but for simplicity, individual consignment volume constraints were not specified. Four portering and cycle courier options were compared, each having different assumptions made about total volume and weight capacity limits and travel speed (Table 1), where capacity information was obtained from equipment suppliers (Newitts, 2019; Kyburz, 2019; Urban Arrow, 2019; Velove, 2019), average walking speed was derived from Open Street Map/ Open Source Routing Machine (OSM/OSRM) data and average cycle speed was based on observations from 30 different cycle courier operators in Europe (PRO-E-BIKE, 2015). The performance metrics that were used for comparing the before-and-after cases were operating costs, $\mathrm{CO}_{2}$ and NOx tailpipe emissions, van driving distance and the amount of time vans were parked by the roadside.

Table 1. Porter and cycle courier capacity and speed assumptions.

\begin{tabular}{llll}
\hline & $\begin{array}{l}\text { Total volume } \\
\text { capacity } \\
(\text { litres })\end{array}$ & $\begin{array}{l}\text { Total weight } \\
\text { capacity } \\
(\mathrm{kg})\end{array}$ & $\begin{array}{l}\text { Travel } \\
\text { speed } \\
\text { (miles/hr) }\end{array}$ \\
\hline 1. Porter using wheeled bag & 200 & 25 & 3.2 \\
\hline 2. Porter using trolley & 430 & 70 & 3.2 \\
\hline 3. Bicycle courier with container & 620 & 125 & 10 \\
\hline 4. Quadcycle courier with container & 1000 & 125 & 10 \\
\hline
\end{tabular}




\subsection{Case study area and carrier characteristics}

The case study was based on the EC2 postcode district of central London, UK, chosen as it was being considered for a portering trial by the carrier. The district includes Shoreditch, Liverpool Street, Barbican and the north-eastern corner of the City of London from St Paul's Cathedral (Figure 1). Also shown in Figure 1 are seven shops that currently act as parcel collection and delivery points on behalf of a separate parcel company and were considered as potentially suitable CDPs in the portering analyses here.

The carrier undertook seven vehicle rounds in this area during the week of 7-11 January 2019 (Monday to Friday), with the unique delivery locations visited shown (Figure 1). The area covered by these rounds was approximately $2.3 \mathrm{~km}$ (1.4 miles) from west to east and $1.6 \mathrm{~km}$ (1 mile) from north to south, with the carrier's manifest data indicating that the 7 drivers visited 624 different buildings during this week with the average delivery round comprising 77 consignments, weighing $618 \mathrm{~kg}$ and with a load volume of 3464 litres. The carriers' vehicles used in the analysis were all 3.5 tonne gross vehicle weight vans with a payload capacity of $1300 \mathrm{~kg}$ and a volume capacity of $10 \mathrm{~m}^{3}$. 


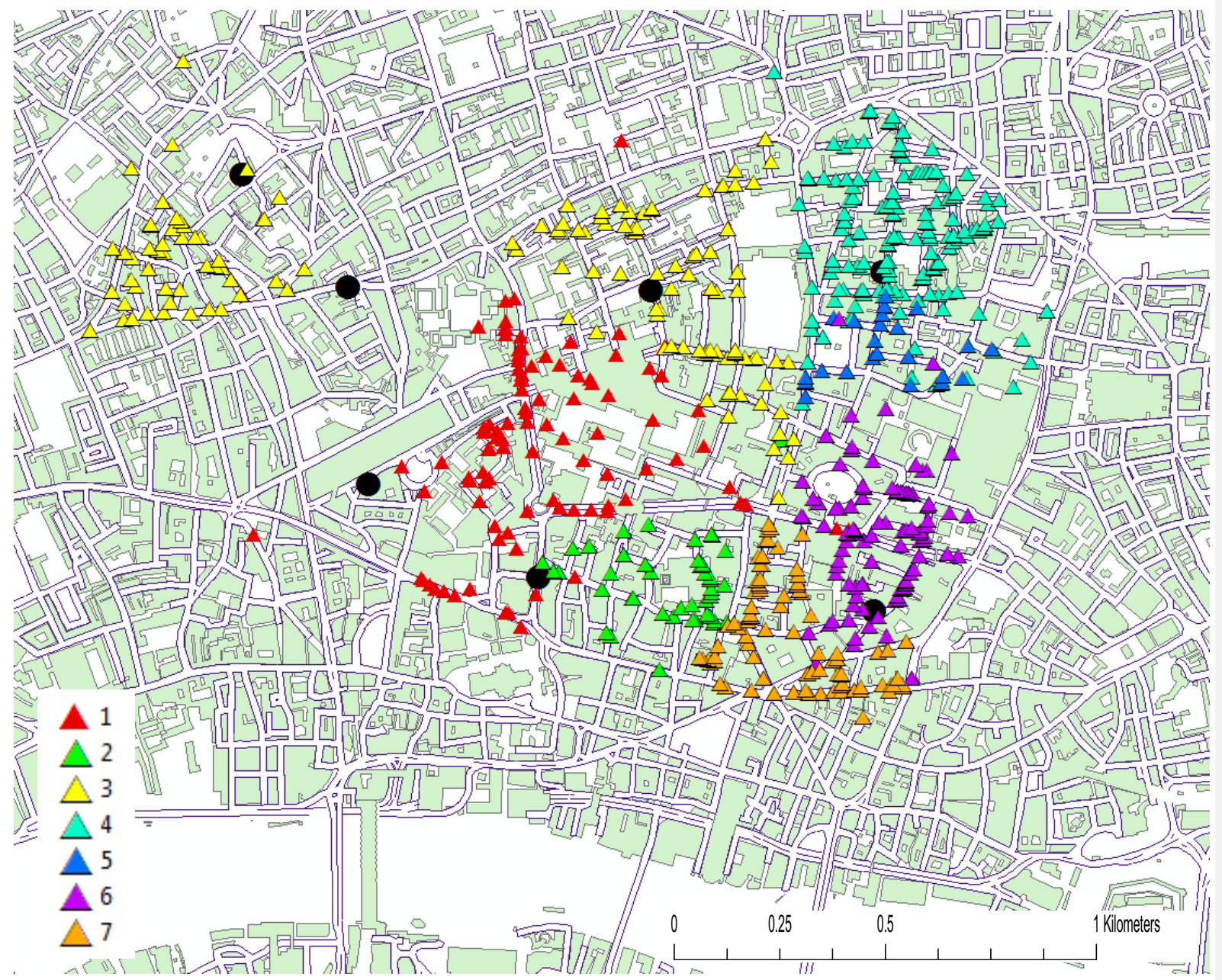

Figure 1. Case study area in central London (delivery locations of 7 carrier rounds, 7-11 January 2019 and proposed CDPs (black circles)).

\subsection{Operating cost assumptions}

Operating cost assumptions are described in this section associated with labour and equipment (section 2.2.1), additional sorting needed at the carrier depot to pre-sort bags for porters or cycle couriers (2.2.2) and the use of CDPs (2.2.3).

\subsubsection{Labour and equipment}

All assumed labour and equipment costs are summarised in Table $2_{p}$ with their derivations

Deleted: and sources explained in this section.

Labour costs for a driver, porter or cycle courier were assumed to be equal and calculated as the current London Living Wage of $£ 10.55 / \mathrm{hr}$ (Living Wage Foundation, 2019) plus assumed 
$35 \%$ overheads covering National Insurance, pension, sick pay and holiday pay (Accounting Services for Business, 2019), giving a total of $£ 14.25 / \mathrm{hr}$.

Van and truck standing and running costs, including tax, insurance, depreciation, fuel, tyres and maintenance, were derived from industry figures (Motor Transport, 2019) and with the London congestion charge of $£ 11.50$ per day added (Transport for London, 2019). Ultra-low emission zone (ULEZ) charges ( $£ 12.50$ per day for vans and $£ 100$ per day for trucks) were not added on the basis that operators would use vehicles meeting Euro 6 standards to avoid them. The congestion charge, which operates independently of the ULEZ charge could also be avoided by using electric vehicles, but their use was not modelled here. In the business-asusual (BAU) case (section 2.4), 3.5t diesel-fuelled vans were used and costs were calculated as $£ 4.13 / \mathrm{hr}+£ 0.41 / \mathrm{km}$. For the modelled portering and cycle courier scenarios, $7.5 \mathrm{t}$ dieselfuelled trucks were assumed and these vehicles were costed at $£ 5.98 / \mathrm{hr}+£ 0.74 / \mathrm{km}$. An 8 hour working day was assumed when converting daily rates (e.g. the congestion charge) to hourly rates.

Vehicle and equipment costs for the walking and cycling options being considered were derived from online quoted purchase prices and through personal contact with manufacturers and users concerning maintenance costs and expected operating lifetimes. For the cycle courier options, the modelled costs included the cost of charging batteries ( $£ 0.02 / \mathrm{hr}$ ) but excluded infrastructure costs (e.g. cycle depot, charging equipment) to provide a fair comparison with the BAU case where vehicle depot costs were not considered. The hourly cost rates were based on the following assumptions:

- Individual wheeled bags ( $£ 0.54 / \mathrm{hr}$ ) - bag purchase cost $£ 72$ (Newitts, 2019); used 8 hours per day for 100 days; average of six bags per porter (derived from case study). 
- $\operatorname{Trolley}(£ 0.62 / \mathrm{hr})$ - purchase cost $£ 4250$; lifetime 7 years; batteries $£ 1020$; battery life 6 years (Kyburz, 2019).

- Electrically-assisted cargo bicycle ( $£ 1.37 / \mathrm{hr})$ - purchase cost $£ 4000$; lifetime 5 years; battery cost: $£ 550$; battery life 2 years; container cost $£ 1279$; container lifetime 5 years (Urban Arrow, 2019).

- Electrically-assisted cargo quadcycle (£1.77/hr) - purchase cost $£ 8762$, (including battery, lights and indicators, remote locking, power (for internal lights and locking), shelving, protective mat); lifetime 5 years; replacement battery cost $£ 550$; battery life 2 years; container cost $£ 1279$; container lifetime 5 years (Velove, 2019).

Table 2. Assumed vehicle/equipment costs.

\begin{tabular}{ll}
\hline Vehicle type & $\begin{array}{l}\text { Vehicle/equipment (including tax, insurance, depreciation, } \\
\text { congestion charge, fuel, tyres, maintenance) }\end{array}$ \\
\hline Truck $(7.5 \mathrm{t})$ & $£ 5.98 / \mathrm{hr}+£ 0.74 / \mathrm{km}$ \\
\hline Van $(3.5 \mathrm{t})$ & $£ 4.13 / \mathrm{hr}+£ 0.41 / \mathrm{km}$ \\
\hline Quadcycle & $£ 1.77 / \mathrm{hr}$ \\
\hline Bicycle & $£ 1.37 / \mathrm{hr}$ \\
\hline Porter + trolley & $£ 0.62 / \mathrm{hr}$ \\
\hline Porter +6 bags & $£ 0.54 / \mathrm{hr}$ \\
\hline
\end{tabular}

\subsubsection{Pre-sorting and packing of bags}

For the portering and cycle courier options considered here, extra time would be needed at the vehicle depot for pre-sorting of parcels into individual loads for the porters or cycle couriers and physical packing of items into bags, using a scanner to record the activity. Based on the authors' direct experience of pre-sorting and packing bags during portering trials (Piecyk et al, 2019), the time required to do this was estimated to be one minute per consignment. For the case study area, this meant total added times associated with this activity ranging between 1.65 hours and 2.17 hours for each day of the week. 


\subsubsection{Collection and delivery points (CDPs)}

In the portering model envisioned here, the carrier makes use of CDPs (general stores, here) operated by a third-party service provider. Charges for this service may relate to both temporary storage of bagged items and time spent by store staff receiving items from drivers and subsequently handing them over to porters or cycle couriers. In the analysis here, a daily storage cost of $£ 1.50$ per $1000 \mathrm{~L}$ was assumed plus a handling charge of $£ 0.50$ per transaction between the store staff and a driver or porter, these being estimated from charges made by a parcel service provider in central London (Parcelly, 2019). In practice, such a service provider may prefer to adopt a simpler charging structure combining the two cost elements.

\subsection{Environmental cost assumptions}

In this research, based on the carrier data, it was determined that two 7.5 tonne gross vehicle weight trucks with a payload of $2500 \mathrm{~kg}$ and a carrying capacity of $34 \mathrm{~m}^{3}$ could be used to support porters or cycle couriers in place of the seven 3.5 tonne gross vehicle weight vans that were used by the carrier. Assumed $\mathrm{CO}_{2}$ and $\mathrm{NOx}$ emission rates for vans and trucks were taken from the Low Carbon Vehicle Partnership (2017) figures for city centre deliveries undertaken by vehicles meeting Euro 6 standards: for vans, $299 \mathrm{~g} / \mathrm{km} \mathrm{CO}_{2}$ and $0.32 \mathrm{~g} / \mathrm{km}$ $\mathrm{NOx}$; for trucks, $520 \mathrm{~g} / \mathrm{km} \mathrm{CO}_{2}$ and $0.67 \mathrm{~g} / \mathrm{km} \mathrm{NOx}$.

\subsection{Quantifying business-as-usual delivery operations}

The carrier's post-delivery manifest data recorded the delivery time at each consignee address and were used to quantify the time spent in the delivery area for each vehicle round on each day and the number of delivery and collection consignments undertaken (Table 3). It was observed that the average time spent in the delivery area was 5 hours and the mean number of consignments handled was 69 , with standard deviation values of 1 hour, 53 minutes and 25.4 consignments, respectively. The average time spent per consignment was 4.35 minutes, which included both driving and performing the delivery or collection. Two rounds (5 and 7) 
had noticeably lighter workloads than the others, averaging less than three hours per day in the delivery area and fewer than 40 consignments per day, on average. Time spent by vans parked by the roadside was not recorded but was estimated to have been around 110 hours, or 3.14 hours per day, on average, if parked for $62 \%$ of the time spent in the delivery area, as observed in other parcel carrier surveys (Allen et al., 2018b). Stem travel times between the carrier's depot, located $15 \mathrm{~km}$ (9 miles) east of the case study area, and the individual delivery round areas were estimated to be around 40 minutes each way using the mapping and routing facilities of OpenStreetMap (OSM) (OpenStreetMap contributors, 2017) and Open Source Routing Machine (OSRM) (Luxen and Vetter, 2011), explained further in section 2.5.

Table 3. Total time (hh:mm) spent by the seven vans in delivery area, 7-11 January 2019 and number of consignments per van (in parentheses).

\begin{tabular}{lllllll}
\hline Round & Mon & Tue & Wed & Thu & Fri & Total \\
\hline 1 & $06: 03(81)$ & $05: 41(102)$ & $05: 47(89)$ & $05: 52(92)$ & $05: 48(78)$ & $29: 11(442)$ \\
\hline 2 & $04: 42(77)$ & $02: 41(70)$ & $04: 37(70)$ & $07: 43(79)$ & $04: 54(84)$ & $24: 37(380)$ \\
\hline 3 & $07: 59(95)$ & $06: 32(90)$ & $07: 10(82)$ & $07: 32(90)$ & $07: 43(92)$ & $36: 56(449)$ \\
\hline 4 & $06: 47(74)$ & $04: 36(62)$ & $05: 31(88)$ & $06: 32(75)$ & $05: 41(63)$ & $29: 07(362)$ \\
\hline 5 & $03: 04(36)$ & $05: 00(32)$ & $01: 00(13)$ & $01: 37(26)$ & $02: 30(28)$ & $13: 11(135)$ \\
\hline 6 & $05: 54(72)$ & $05: 56(95)$ & $05: 02(92)$ & $07: 29(99)$ & $06: 15(102)$ & $30: 36(460)$ \\
\hline 7 & $03: 21(38)$ & $01: 31(22)$ & $03: 12(38)$ & $03: 21(54)$ & $03: 01(45)$ & $14: 26(197)$ \\
\hline Total & $37: 50(473)$ & $31: 57(473)$ & $32: 19(472)$ & $40: 06(515)$ & $35: 52(492)$ & $178: 04(2425)$ \\
\hline
\end{tabular}

Vehicle distance data were not recorded by the parcel carrier due to the use of subcontractors; however, the total distance driven within the delivery area (by 7 drivers over 5 days) was estimated to be $336 \mathrm{~km}$, calculated as an average speed, including all stopped time, of $1.89 \mathrm{~km} / \mathrm{h}$, found from earlier carrier surveys in central London (Allen et al., 2018b) multiplied by the time spent in the delivery area of 178 hours. Added to this was a total stem travel distance of $1014 \mathrm{~km}$ estimated from OSM/OSRM data, giving an average daily round distance of $38.6 \mathrm{~km}$, of which $75 \%$ was the stem distance. The average distance driven within the delivery area, excluding stem mileage, was estimated to be $9.6 \mathrm{~km}$. 
Total emissions for the 7 vans over 5 working days were estimated to be $403.7 \mathrm{kgCO}_{2}$ and $0.43 \mathrm{kgNOx}$ using the emission rates stated in section 2.3. Total diesel consumption was estimated to be 152.9 litres, derived by dividing the total $\mathrm{CO}_{2}$ emissions by the amount of $\mathrm{CO}_{2}$ generated from a litre of diesel, that is $2.64 \mathrm{kgCO}_{2} /$ litre (Comcar, 2019). The total financial cost for the week was estimated to be $£ 4,648$, calculated as $£ 3,179$ labour costs along with $£ 1,469$ vehicle costs, based on the cost assumptions (section 2.2.1). Depot operating costs were not considered here as they were assumed to be the same between the different operating methods; however, extra sorting and packing costs associated with using porters or cycle couriers were included (see section 2.2.2).

\subsection{Portering algorithm}

An algorithm was designed to model the last-mile interface between drivers and porters (or, equivalently, cycle couriers) previously described, to search for the most optimal:

(i) CDPs the drivers would visit from among a given set of available locations;

(ii) van routes for drivers to visit the CDPs and undertake their other work (collections and deliveries of heavier items);

(iii) number of porters needed;

(iv) porter routes, to enable collection of parcels from one or more CDPs and delivery to consignees.

The algorithm is a tabu search heuristic that uses a randomized constructive procedure and a greedy and fast local search improvement method which is based on the well-known 2-OPT mechanism proposed for the Travelling Salesman Problem (TSP) (Croes, 1958). The constructive algorithm computes the route of the drivers, considering the heavy and large items that cannot be delivered by the porters, obtained by solving a TSP. The Concorde algorithm was used to solve the derived TSP (University of Waterloo, 2016). The algorithm 
then forms the consignee delivery clusters by choosing a first customer in each cluster at random, and then iteratively adding other customers to the clusters in such a way that lowest cost is achieved without violating the weight and volume limits.

Let $V$ be the set of all the customers and let $\bar{V}$ be the set of customers not assigned to any cluster. Initially, we set $V=\bar{V}$. Then, in order to build the next cluster we perform the following steps.

1. Select randomly $i \in \bar{V}$. Weight capacity limit $=W$. Volume capacity limit $=L$.

2. $C=\{i\}, \bar{w}=W-w_{i}$, where $w_{i}$ is the total weight of all the items to be delivered to customer $i$ and $\bar{l}=L-l_{i}$, where $l_{i}$ is the total volume of all the items to be delivered to customer $i$. Set $\operatorname{Cost}=\operatorname{TSP}(C)$, where $\operatorname{TSP}(C)$ is the cost of the TSP over the nodes in $C$ obtained by the best insertion algorithm.

3. While $\bar{w}>0 ; \bar{l}>0$ and $\bar{V} \backslash C \neq \emptyset$ :

Find $j \in \bar{V} \backslash C$ such that $\bar{w}-w_{j} \geq 0, \bar{l}-l_{j} \geq 0$ and $\operatorname{TSP}(C \cup\{j\})$ is minimum. If there is such customer $j$ satisfying these conditions then set $C=$ $C \cup\{j\}, \operatorname{Cost}=\operatorname{TSP}(C), \bar{w}=\bar{w}-w_{j}$ and $\bar{l}=\bar{l}-l_{j}$.

4. New cluster $C$ built. Set $\bar{V}=\bar{V} \backslash C$ and go to step 1 .

Once all the clusters have been created, each cluster is assigned to a porter, on which the 2OPT heuristic is run. The 2-OPT heuristic explores alternative orderings of the customers that have been assigned to a given porter to improve the intra-cluster routings.

Then a tabu search algorithm is used for inter-cluster allocations, where the neighbourhood of the tabu search is defined as the best move of a customer to a different porter in such a way that the selected customer does not belong to the tabu list. When exploring the best insertion 
of a given customer to the route assigned to a different porter we check that all conditions described in (3) of the construction algorithm are satisfied. For each possible insertion, we compare route costs and perform the movement that leads to the total lower cost. Each run of the tabu search was limited to 600 seconds and the size of the tabu list was fixed to 5 .

Drivers start and end from a given vehicle depot, while porter routes commence and end at selected CDP facilities, where these may vary between porters and where the start and end CDPs may differ (e.g. route may visit two or more CDPs). Intermediate visits to CDP facilities to pick up more items for delivery will usually be required due to the porters' carrying capacity weight and volume limits. An example illustration of driver and porter routes output by the algorithm is shown in Figure 2; this shows crow-flight travel paths between consecutive points and not actual paths that would be taken since the algorithm has no information about the road network other than travel times between points as obtained from OSM/OSRM data.

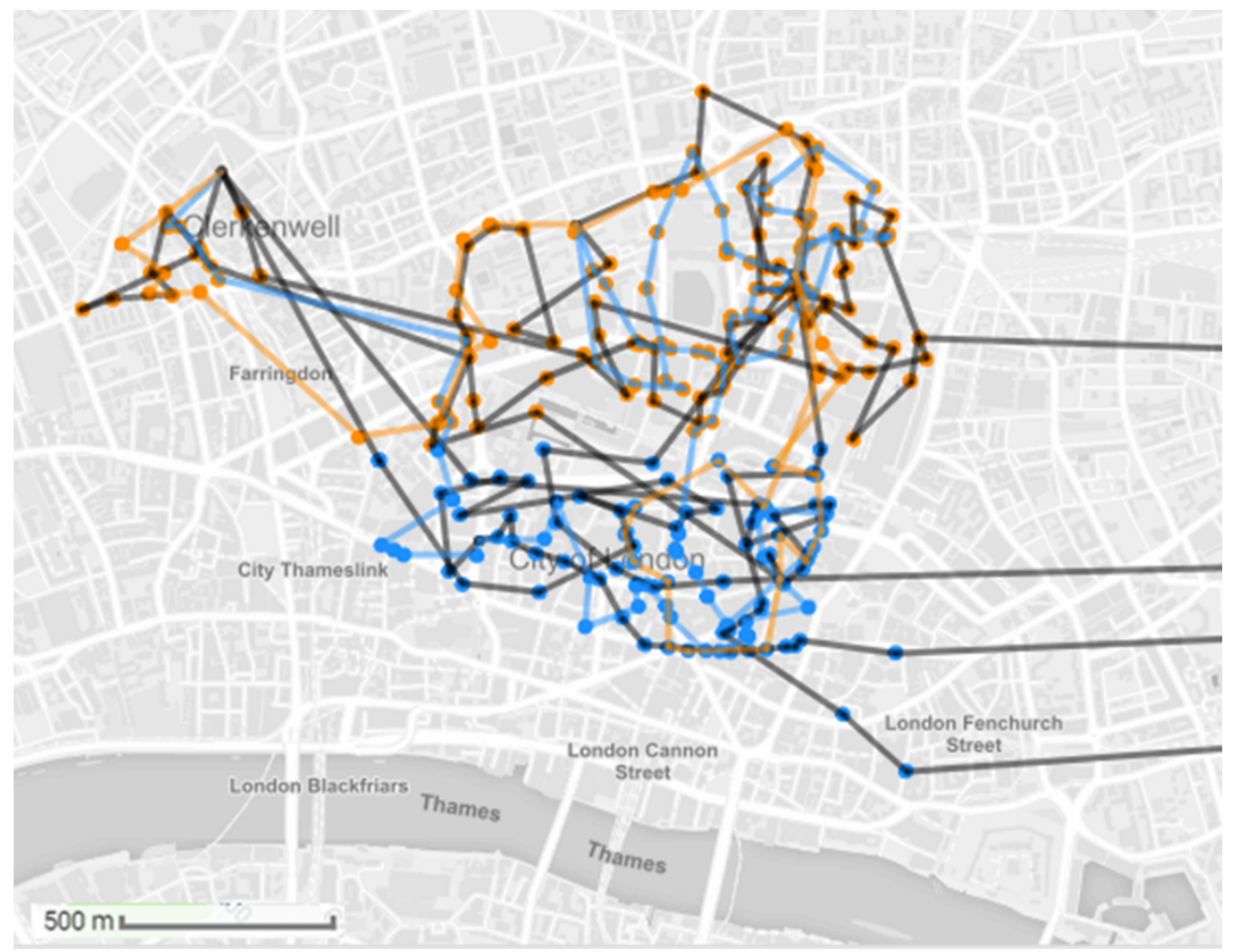


Figure 2. Example crow-flight representation of portering routes (blue and orange) and two vehicle routes (both grey) for one day (depot $15 \mathrm{~km}$ to east not shown) (Credit: Map data (C) OpenStreetMap contributors, CC-BY-SA, Imagery (C) Mapbox).

The required inputs to the algorithm, with all locations in latitude, longitude format, are:

(i) CDP location(s)

(ii) Vehicle (van or truck) depot location;

(iii)Number of vehicles to be used, their individual carrying capacity and for each vehicle, a list of the individual consignment weights, volumes and delivery (or collection) locations. In the case study examples, two trucks, each with a carrying capacity of $2.5 \mathrm{t}$ were assumed, being the minimum number needed to carry the total load each day. Items were divided between the two vehicles on an east/west basis by sorting the manifest data by longitude values and splitting approximately halfway by total item weight.

(iv)Origin-destination (OD) driving and walking (or cycling) matrices that specify times (or any other defined generalised cost) between all pairs of locations. Here, combined travel and delivery times were used as the cost function, where travel times were obtained from OSM/OSRM data. The times provided by OSRM were based on their default settings (as per version 5.18), which accounted for different road types and restrictions and included turning penalties. The travel time outputs of the algorithm were later adjusted to more accurately represent reported speeds (described later in this section). Average delivery times of 3 and 5 minutes per location for porters and drivers respectively were assumed, based on earlier carrier surveys (Allen et al., 2018b), the difference reflecting the extra time needed by drivers to unload parcels and to walk from and to the parked vehicle as parking directly outside a delivery 
address was rarely possible. For simplicity and consistency, it was also assumed that a visit to a CDP would take 3 minutes for a porter and 5 minutes for a driver.

(v) Parameter values specifying: maximum consignment weight (5kg specified here) and total load weights and volumes that porters (or cycle couriers) may carry at any given time (Table 1); maximum working hours for porters; hourly cost rates of porters and of drivers and their vehicles; and a penalty cost per porter to minimise the number of porters utilised (a high value was specified here).

Minimising the number of porters used was considered desirable in a practical setting to reduce organisational requirements and to give individual porters enough work, however, the modelled penalty cost was not included in the cost reporting as it was not considered to be a real cost.

The algorithm uses an objective function that minimises the total cost of porters, drivers and the time utilisation of the vehicles. The essentially fixed costs of pre-sorting and packing bags (section 2.2.2) and of using CDP facilities (section 2.2.3) were not included in the algorithm as they would not affect the routing solutions produced but they were subsequently added to the total cost of the solutions. Vehicle emissions were also computed, post-optimisation but were not included within the algorithm's objective function, as solving the TSP to minimise driver times was deemed adequate to help reduce environmental impacts.

Direct and derived outputs from the algorithm included: travel times and speeds; time spent at delivery addresses; distances driven, walked or cycled; parcel weights and volumes carried; use of CDPs, in terms of parcel weights, volumes and how many times they were visited by drivers and porters; environmental and financial costs. In post-processing of the algorithm's output, driving times were factored by 1.81 as the average driving speed of $14.5 \mathrm{mph}$ in the OSM/OSRM data for central London was found to be 1.81 times faster than the published 
statistic of 8mph (Mayor of London and Transport for London, 2018). Similarly, cycling times were corrected using a factor of 1.5 based on the ratio of average cycling speed in the OD matrices $(15 \mathrm{mph})$ to the practical mean speed of cargo cycles $(10 \mathrm{mph})$ found from observations of around 30 different cycle courier operators in Europe (PRO-E-BIKE, 2015). The average walking time found in the OSM/OSRM data was $3.2 \mathrm{mph}$ which was considered satisfactory for use here.

\section{Results}

The portering algorithm was run for each of the portering and cycle courier options considered (Table 1) and for each of the five working days (7-11 January 2019), using the carrier data to specify deliveries and collections to be made. The modelled results indicated substantial environmental and financial savings for all of the portering and cycle courier options when compared with the BAU case (relative savings compared in Figure ${ }_{\text {w }}$ with absolute values in Table 4). Key reasons for the savings were the reduced number of dieselfuelled vehicles being used (from 7 vans to 2 trucks) and the reduced numbers of personnel involved (from seven to three or four). Although trucks were used in the portering and cycle courier scenarios instead of smaller, more fuel-efficient vans, the substantial van mileage savings (68\%-69\%) meant substantial fuel consumption and $\mathrm{CO}_{2}$ savings (44\%-45\%) and NOx savings (33\%-34\%).

In absolute terms, the emissions savings for this carrier for one week in the case study area were estimated to be $182.7 \mathrm{~kg} \mathrm{CO}$ and $0.147 \mathrm{~kg} \mathrm{NOx}$. There was very little difference in emissions savings between each of the portering or cycle courier options since the driving routes only varied slightly between them according to which CDPs were selected for use. The portering and cycle courier scenarios were estimated to reduce the total amount of van or truck curbside parking by $43 \%-45 \%$, although the use of a truck rather than a van would take 
up more space at each stopping point. From a financial perspective, the bicycle and quadcycle courier options were estimated to be slightly more cost effective than using porters, both being $39 \%$ cheaper compared to the BAU case, compared to the $34 \%$ and $37 \%$ savings for porters using wheeled bags and trollies respectively.

Table 4. Summary comparison of modelled results (business-as-usual against mixed van and portering/cycle courier operations) for Monday $7^{\text {th }}$ January to Friday $11^{\text {th }}$ January 2019.

\begin{tabular}{|l|l|l|l|l|l|l|}
\hline \multirow{2}{*}{} & \multicolumn{3}{|l|}{$\begin{array}{l}\text { Totals for working week relating to } \\
\text { Vehicles and people }\end{array}$} & \multicolumn{2}{l|}{ van/truck use } \\
\cline { 2 - 7 } $\begin{array}{l}\text { Operating } \\
\text { scenario }\end{array}$ & $\begin{array}{l}\text { Average } \\
\text { number } \\
\text { required }\end{array}$ & Cost $(£)$ & $\begin{array}{l}\text { CO2 } \\
(\mathrm{kg})\end{array}$ & $\begin{array}{l}\mathrm{NOx} \\
(\mathrm{kg})\end{array}$ & $\begin{array}{l}\text { Van } \\
\text { distance } \\
(\mathrm{km})\end{array}$ & $\begin{array}{l}\text { Van } \\
\text { parking } \\
(\mathrm{h})\end{array}$ \\
\hline $\begin{array}{l}\text { Business as } \\
\text { usual }\end{array}$ & 7 vans & 4648 & 403.7 & 0.432 & 1350 & 110 \\
\hline $\begin{array}{l}\text { Portering } \\
\text { (200L bag) }\end{array}$ & $\begin{array}{l}2 \text { trucks }+ \\
2 \text { porters }\end{array}$ & 3073 & 226.3 & 0.292 & 435 & 62.4 \\
\hline $\begin{array}{l}\text { Portering } \\
\text { (trolley) }\end{array}$ & $\begin{array}{l}2 \text { trucks }+ \\
2 \text { porters }\end{array}$ & 2951 & 222.8 & 0.287 & 428 & 61.8 \\
\hline $\begin{array}{l}\text { Bicycle } \\
\text { courier }\end{array}$ & $\begin{array}{l}2 \text { trucks }+ \\
1.2 \text { bicycles }\end{array}$ & 2817 & 221.2 & 0.285 & 425 & 60.8 \\
\hline $\begin{array}{l}\text { Quadcycle } \\
\text { courier }\end{array}$ & $\begin{array}{l}2 \text { trucks }+ \\
1 \text { quadcycle }\end{array}$ & 2814 & 221.0 & 0.285 & 425 & 60.8 \\
\hline
\end{tabular}

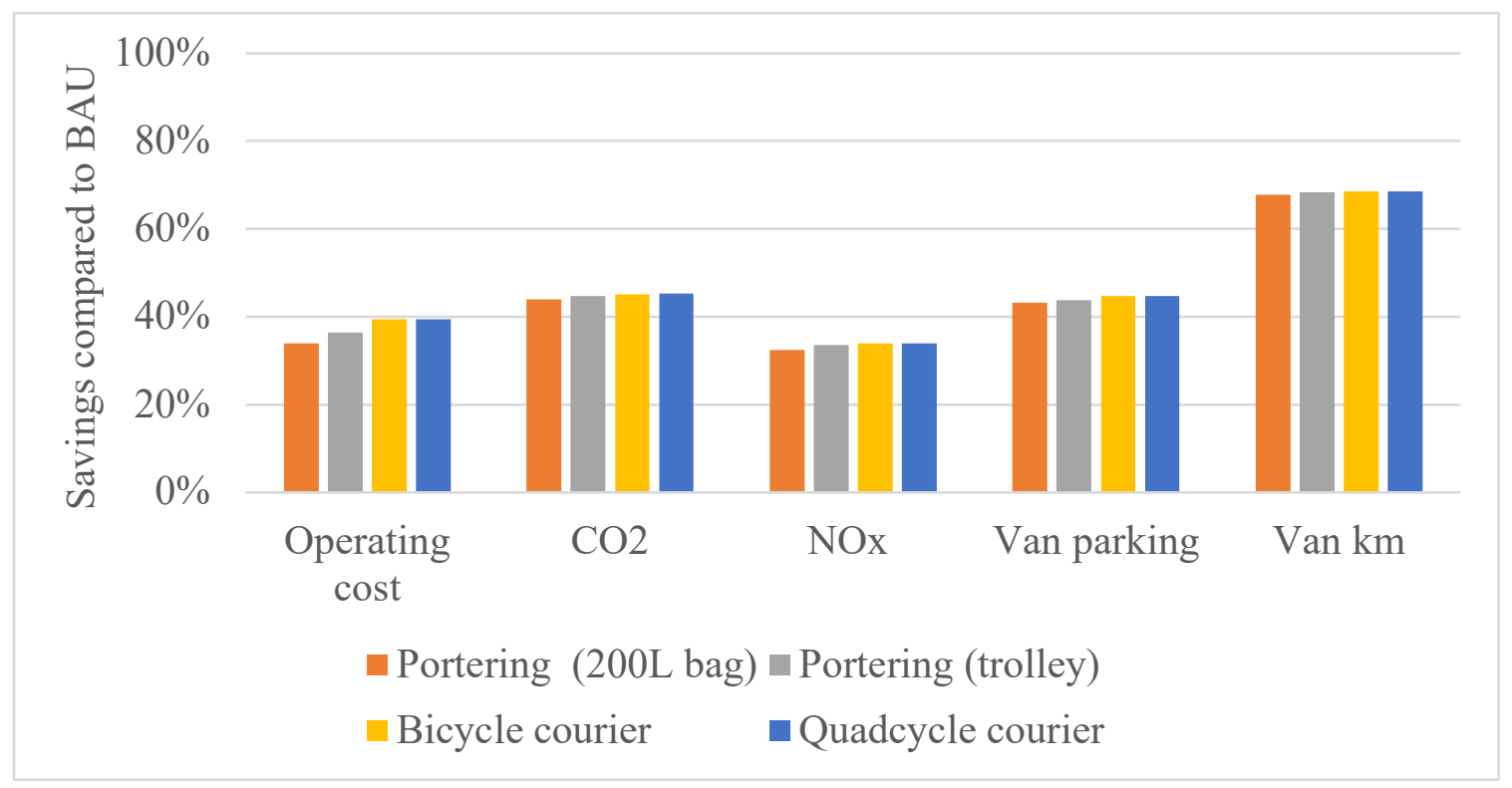

Figure 3. Percentage savings of modelled results (business-as-usual against mixed van and portering/cycle courier operations). 
More detailed analyses of the individual driver and porter workloads each day for each scenario provided greater understanding of the results, as illustrated here for Monday $7^{\text {th }}$ January 2019 (Table 5 to Table 8). In all cases, the porters or cycle couriers made $50 \%$ of all the deliveries, dictated by the fact that $50 \%$ of the consignments were $5 \mathrm{~kg}$ or under. In the case of portering using 200L wheeled bags (Table 4), the total time taken was modelled to be $37.1 \%$ less than in the BAU case, which suggests that items could have been delivered sooner, while the financial savings were estimated to be $35.4 \%$. Since the portering algorithm does not attempt to balance workloads, one porter was modelled to work for nearly 8 hours while the other worked for just under 4 hours, walking $13.4 \mathrm{~km}$ and $9 \mathrm{~km}$, respectively.

The two truck drivers were occupied for just under 8 hours and 10 hours, respectively. If the latter round time were considered too long, in practice, then a third truck and driver would have to be used, at an increased cost (not modelled here). The ratios of driver travel time to the time spent making deliveries or collections were 33\%:67\% and 30\%:70\% for the two drivers, which corresponded approximately with carrier survey data that showed vehicles parked for around $62 \%$ of round time (Allen et al., 2018b).

Where the porters were equipped with 430L trollies, the increased carrying capacity meant approximately $50 \%$ fewer visits to CDPs, leading to additional savings ( $2 \%-4 \%$ greater) in terms of diesel consumption, emissions, time, distance and estimated cost (Table 6). This meant fuel consumption and $\mathrm{CO}_{2}$ savings, compared to the BAU case, of $44.4 \%$ and $\mathrm{NOx}$ savings of $33 \%$, as well as cost savings of $39.4 \%$.

The use of bicycle couriers with even greater carrying capacity (620L) and faster travel speeds (Table 1), led to slightly higher savings across all the performance measures considered (Table 7). Driving distance savings were $68.3 \%$ equating to fuel and $\mathrm{CO}_{2}$ savings of $44.9 \%$ and NOx savings of $33.7 \%$; time and cost savings were $45.6 \%$ and $42.5 \%$, 
compared to the BAU case. Although two bicycle couriers were required on the Monday, on all other days of the week it was possible to utilise a single bicycle courier as the time required was lower than the specified 8.5-hour limit. Where a single quadcycle courier with a 1000L carrying capacity was used (Table 8), results were very similar to those found when using bicycle couriers (Table 7), indeed all the results were fairly insensitive to the choice of portering or cycle courier method.

Table 5. Portering with 200L wheeled bag, Monday $7^{\text {th }}$ January 2019

\begin{tabular}{|l|l|l|l|l|l|l|l|}
\cline { 2 - 8 } \multicolumn{1}{c|}{} & Driver 1 & Driver 2 & Porter 1 & Porter 2 & Total & Porter \% & Savings \% \\
\hline Travel time & $02: 37: 23$ & $02: 56: 39$ & $02: 38: 15$ & $01: 45: 03$ & $09: 57: 21$ & $44 \%$ & \\
\cline { 1 - 1 } $\begin{array}{l}\text { Delivery/collection } \\
\text { time }\end{array}$ & $05: 20: 00$ & $07: 00: 00$ & $05: 06: 00$ & $02: 06: 00$ & $19: 32: 00$ & $37 \%$ & \\
\hline Total time & $07: 57: 23$ & $09: 56: 40$ & $07: 44: 15$ & $03: 51: 03$ & $29: 29: 21$ & $39 \%$ & $37.1 \%$ \\
\hline Cost (£) & 193.47 & 237.27 & 144.91 & 69.93 & 645.58 & $33 \%$ & $35.4 \%$ \\
\hline \#visits to CDPS & 4 & 4 & 8 & 4 & 20 & $60 \%$ & \\
\hline \#deliveries & 57 & 71 & 93 & 37 & 258 & $50 \%$ & \\
\hline \#collections & 5 & 10 & 0 & 0 & 15 & $0 \%$ & \\
\hline Items weight (kg) & 1784 & 1588 & 157 & 85 & 3615 & $7 \%$ & \\
\hline Items volume (litres) & 9943 & 8661 & 1178 & 540 & 20321 & $8 \%$ & \\
\hline Distance (km) & 43.9 & 48.8 & 13.4 & 9.0 & 115.1 & $19 \%$ & $66.2 \% *$ \\
\hline Diesel used (litres) & 8.65 & 9.61 & 0 & 0 & 18.3 & $0 \%$ & $41.2 \%$ \\
\hline $\mathrm{CO}_{2}(\mathrm{~kg})$ & 22.8 & 25.4 & 0 & 0 & 48.2 & $0 \%$ & $41.2 \%$ \\
\hline $\mathrm{NOx}^{(\mathrm{kg})}$ & 0.0294 & 0.0327 & 0 & 0 & 0.1 & $0 \%$ & $29.2 \%$ \\
\hline
\end{tabular}

* Driving distance savings

Table 6. Portering with 430L trolley, Monday $7^{\text {th }}$ January 2019

\begin{tabular}{|l|l|l|l|l|l|l|l|}
\cline { 2 - 7 } \multicolumn{1}{c|}{} & Driver 1 & Driver 2 & Porter 1 & Porter 2 & Total & Porter \% & Savings \% \\
\hline Travel time & $02: 22: 15$ & $02: 46: 36$ & $02: 06: 51$ & $01: 19: 43$ & $08: 35: 25$ & $40 \%$ & \\
\cline { 1 - 1 } $\begin{array}{l}\text { Delivery/collection } \\
\text { time }\end{array}$ & $05: 10: 00$ & $06: 55: 00$ & $04: 00: 00$ & $02: 51: 00$ & $18: 56: 00$ & $36 \%$ & \\
\hline Total time & $07: 32: 15$ & $09: 41: 36$ & $06: 06: 51$ & $04: 10: 43$ & $27: 31: 25$ & $37 \%$ & $41.3 \%$ \\
\hline Cost (£) & 182.69 & 230.79 & 113.48 & 77.97 & 604.93 & $32 \%$ & $39.4 \%$ \\
\hline \#visits to CDPs & 2 & 3 & 3 & 2 & 10 & $50 \%$ & \\
\hline \#deliveries & 57 & 71 & 76 & 54 & 258 & $50 \%$ & \\
\hline \#collections & 5 & 10 & 0 & 0 & 15 & $0 \%$ & \\
\hline Items weight (kg) & 1784 & 1588 & 137 & 106 & 3615 & $7 \%$ & \\
\hline Items volume (litres) & 9943 & 8661 & 1049 & 669 & 20321 & $8 \%$ & \\
\hline
\end{tabular}




\begin{tabular}{|l|l|l|l|l|l|l|l|}
\cline { 6 - 8 } Distance $(\mathrm{km})$ & 40.8 & 46.9 & 10.8 & 6.9 & 105.4 & $17 \%$ & $68.0 \%$ \\
\hline Diesel used (litres) & 8.04 & 9.23 & 0 & 0 & 17.3 & $0 \%$ & $44.4 \%$ \\
\hline $\mathrm{CO}_{2}(\mathrm{~kg})$ & 21.2 & 24.4 & 0 & 0 & 45.6 & $0 \%$ & $44.4 \%$ \\
\hline $\mathrm{NOx}(\mathrm{kg})$ & 0.0273 & 0.0314 & 0 & 0 & 0.1 & $0 \%$ & $33.0 \%$ \\
\hline
\end{tabular}

Table 7. Bicycle courier with $620 \mathrm{~L}$ container, Monday $7^{\text {th }}$ January 2019

\begin{tabular}{|l|l|l|l|l|l|l|l|}
\cline { 2 - 7 } \multicolumn{1}{c|}{} & Driver 1 & Driver 2 & Biker 1 & Biker 2 & Total & Biker \% & Savings \% \\
\hline Travel time & $02: 15: 47$ & $02: 48: 57$ & $00: 56: 38$ & $00: 49: 17$ & $06: 50: 39$ & $26 \%$ & \\
\cline { 1 - 1 } $\begin{array}{l}\text { Delivery/collection } \\
\text { time }\end{array}$ & $05: 05: 00$ & $06: 45: 00$ & $04: 06: 00$ & $02: 45: 00$ & $18: 41: 00$ & $37 \%$ & \\
\hline Total time & $07: 20: 47$ & $09: 33: 57$ & $05: 02: 38$ & $03: 34: 17$ & $25: 31: 39$ & $34 \%$ & $45.6 \%$ \\
\hline Cost (£) & 177.89 & 228.50 & 98.76 & 69.10 & 574.24 & $29 \%$ & $42.5 \%$ \\
\hline \#visits to CDPs & 1 & 1 & 3 & 2 & 7 & $71 \%$ & \\
\hline \#deliveries & 57 & 71 & 78 & 52 & 258 & $50 \%$ & \\
\hline \#collections & 5 & 10 & 0 & 0 & 15 & $0 \%$ & \\
\hline Items weight (kg) & 1784 & 1588 & 148 & 95 & 3615 & $7 \%$ & \\
\hline Items volume (litres) & 9943 & 8661 & 994 & 723 & 20321 & $8 \%$ & \\
\hline Distance (km) & 39.6 & 47.3 & 15.8 & 13.8 & 116.4 & $25 \%$ & $68.3 \%$ \\
\hline Diesel used (litres) & 7.79 & 9.31 & 0 & 0 & 17.1 & $0 \%$ & $44.9 \%$ \\
\hline $\mathrm{CO}_{2}(\mathrm{~kg})$ & 20.6 & 24.6 & 0 & 0 & 45.2 & $0 \%$ & $44.9 \%$ \\
\hline NOx (kg) & 0.0265 & 0.0317 & 0 & 0 & 0.1 & $0 \%$ & $33.7 \%$ \\
\hline
\end{tabular}

Table 8. Quadcycle courier with $1000 \mathrm{~L}$ container, Monday $7^{\text {th }}$ January 2019

\begin{tabular}{|l|l|l|l|l|l|l|}
\cline { 2 - 6 } \multicolumn{1}{c|}{} & Driver 1 & Driver 2 & Biker & Total & Biker \% & Savings \% \\
\hline Travel time & $02: 15: 47$ & $02: 56: 27$ & $01: 46: 09$ & $06: 58: 23$ & $25 \%$ & \\
\hline Delivery/collection time & $05: 05: 00$ & $06: 45: 00$ & $06: 39: 00$ & $18: 29: 00$ & $36 \%$ & \\
\hline Total time & $07: 20: 47$ & $09: 41: 27$ & $08: 25: 09$ & $25: 27: 23$ & $33 \%$ & $45.7 \%$ \\
\hline Cost (£) & 177.89 & 232.33 & 169.96 & 580.18 & $29 \%$ & $41.9 \%$ \\
\hline \#visits to CDPs & 1 & 1 & 2 & 4 & $50 \%$ & \\
\hline \#deliveries & & 71 & 130 & 258 & $50 \%$ & \\
\hline \#collections & 57 & 10 & 0 & 15 & $0 \%$ & \\
\hline Items weight (kg) & 5 & 1784 & 243 & 3615 & $7 \%$ & \\
\hline Items volume (litres) & 9943 & 8661 & 1718 & 20321 & $8 \%$ & \\
\hline Distance (km) & 39.6 & 49.0 & 28.5 & 117.1 & $24 \%$ & $67.7 \%$ \\
\hline Diesel used (litres) & 7.79 & 9.66 & 0 & 17 & $0 \%$ & $43.8 \%$ \\
\hline $\mathrm{CO}_{2}(\mathrm{~kg})$ & 20.6 & 25.5 & 0 & 46.1 & $0 \%$ & $43.8 \%$ \\
\hline $\mathrm{NOx}^{(\mathrm{kg})}$ & 0.0265 & 0.0329 & 0 & 0.0594 & $0 \%$ & $32.4 \%$ \\
\hline
\end{tabular}


Factoring the modelled results found here for one week only suggested that, over the business-as-usual case for the area of London studied, the carrier could reduce $\mathrm{CO}_{2}$ emissions by $9500 \mathrm{~kg} /$ year and NOx emissions by $7.64 \mathrm{~kg} /$ year. Annual driving distance could be reduced by $48,100 \mathrm{~km}$ and the amount of parked time at the curbside could be reduced by 2558 hours. Scaling up the modelled emissions savings to London's Central Activities Zone, an area approximately 10 times bigger than the modelled case study area and with estimated total annual parcel delivery distance of 15 million km (Piecyk et al, 2019), annual emissions savings could be in the region of 2 million $\mathrm{kg} \mathrm{CO}_{2}$ and $1633 \mathrm{~kg}$ NOx if all carriers utilised porters or cycle couriers.

\section{Discussion and conclusions}

The results have suggested that substantial environmental and financial savings may be made through using porters or cycle couriers for parcel deliveries. These were for an example using real carrier data where only around half of all consignments were light enough (5kg or less) for delivery by a porter or cycle courier. It is anticipated that even greater savings could be attained for carriers with lighter parcel weight profiles (e.g. those mainly serving the business-to-consumer (B2C) market), since more items could then be delivered by porters or cycle couriers. The use of porters or cycle couriers may also confer an advantage to other road users in the reduction of curbside parking by vans or trucks. A potential negative point with the use of bicycles or quadcycles, however, is that they may cause some nuisance for pedestrians if parked on the sidewalk or, if a quadcycle has to be parked by the curbside due to its larger size, then little or no parking benefit may accrue.

The use of porters or cycle couriers alongside van drivers, as proposed here, adds system complexity (e.g. pre-sorting parcels, packing bags and dropping off to CDPs) that may act as a barrier to more widespread implementation. To mitigate this, a preferred solution for a 
parcel carrier may be to outsource some or all the associated added tasks (e.g. sorting parcels, packing bags, delivery by porter or cycle courier) to a third-party service provider (e.g. a crowdshipping company). A possible concern is the security of handing over parcels to a third party but this may be mitigated by using a tracking and proof-of-delivery system (e.g. via a mobile phone app). Consideration would also have to be given to treatment of any express deliveries and of failed deliveries, particularly for B2C parcels.

As the modelled environmental and financial savings were similar for using porters or cycle couriers, the choice of which to use may be dictated by the availability and skills of suitable personnel, where reliability, good local knowledge (e.g. of street and building locations) and physical fitness are needed. Delivery distances may also be a consideration, as cycle couriers will typically be able to cover longer distances than porters. It may be possible to source personnel from among individuals already working as part-time couriers (e.g. for take-out meal delivery companies) and this might allow these couriers to make up a full day's work across food and parcel deliveries. With the rise of internet-based platform providers for taxi services and takeaway meal delivery, this method of hiring casual labour has been growing rapidly in the UK and elsewhere, albeit with concerns about working conditions and employee rights (Taylor et al, 2017). With expected continuing growth in parcel delivery demand and corresponding growth in walking and cycling couriers, there is considerable scope to see a switch to more sustainable last-mile parcel delivery for the wider benefit of society. 


\section{Acknowledgments}

The authors gratefully acknowledge the EPSRC for funding this work through its financial support of Freight Traffic Control 2050 (www.ftc2050.com), EPSRC Grant Reference: EP/N02222X/1. Responsibility for the contents of the paper rests with the authors.

\section{References}

Accounting Services for Business (2019). Calculators, https://accountingservicesforbusiness.co.uk/resources/calculators/ (Accessed 28 June 2019)

Allen, J., Bektas, T., Cherrett, T.J., Bates, O., Friday, A., McLeod, F.N., Piecyk, M., Piotrowska, M., Nguyen, T., Wise, S. (2018a). The scope for pavement porters: Addressing the challenges of last-mile parcel delivery in London. Transportation Research Record, 2672(9), 1-13.

Allen, J., Piecyk, M., Piotrowska, M., McLeod, F., Cherrett, T., Ghali, K., Nguyen, T., Bektas, T., Bates, O., Friday, A., Wise, S., Austwick, M. (2018b). Understanding the impact of e-commerce on last-mile light goods vehicle activity in urban areas: The case of London. Transportation Research Part D: Transport and Environment 61, 325-338.

Baker, L. (2019). Today’s Pickup: UPS hit with \$33.8 million in NYC parking fines; FedEx, \$14.9 million. https://www.freightwaves.com/news/todayspickup/ups-fedex-parking-fines (Accessed 2 January 2020).

Browne, M., Allen, J. and Leonardi, J. (2011). Evaluating the use of an urban consolidation centre and electric vehicles in central London, IATSS Research, 35(1), 1-6.

Business of Apps (2019). Deliveroo Revenue and Usage Statistics (2019). Available at: http://www.businessofapps.com/data/deliveroo-statistics/ (Accessed 28 June 2019)

Comcar (2019). $\mathrm{Kg} \mathrm{CO}_{2}$ per litre of diesel

https://comcar.co.uk/emissions/co2litre/index.cfm?\&fueltype=diesel (Accessed 28 June 2019)

Conway, A., Fatisson, P., Eickemeyer, P., Cheng, J., Peters, D. (2012). Urban microconsolidation and last mile goods delivery by freight-quadcycle in Manhattan: opportunities and challenges. In: Conference proceedings. Transportation Research Board $91^{\text {st }}$ Annual Meeting, Washington D.C., USA.

Croes, G.A. (1958). A method for solving traveling-salesman problems. INFORMS, 6(6), 791-908. DOI: 10.1287/opre.6.6.791

Cyclelogistics (2011). Short history of cargo cycling. http://cyclelogistics.eu/docs/119/D2_1_Guide_to_effective_strategies_for_cyclelogistics.pdf (Accessed 28 June 2019) 
Cyclelogistics (2014). Final Public Report.

http://cyclelogistics.eu/docs/111/D6_9_FPR_Cyclelogistics_print_single_pages_final.pdf (Accessed 28 June 2019)

Dablanc, L., Morganti, E., Arvidsson, N., Woxenius, J., Browne, M. \& Saidi, N. (2017). The rise of on-demand 'Instant Deliveries' in European cities. Supply Chain Forum: An International Journal, 18(4), 203-217.

DC Velocity (2016). DHL Express opens "walking courier" facility in Manhattan financial district, 7 July. http://www.dcvelocity.com/articles/20160707-dhl-express-opens-walkingcourier-facility-in-manhattan-financial-district/ (Accessed 28 June 2019)

DHL (2016). PT Walking Courier (Mid-Town - East 47th and Park).

http://www.dhl.com/content/dam/downloads/g0/about_us/logistics_insights/dhl_self_driving _vehicles.pdf (Accessed 28 June 2019)

DHL (2018). DHL expands presence in New York city area to support burgeoning international trade. https://www.logistics.dhl/us-en/home/press/press-archive/2018/dhlexpands-presence-in-new-york-city-area-to-support-burgeoning-international-trade.html (Accessed 28 June 2019)

Kyburz (2019). eTrolley 4+1 - For a punctual postal service. https://kyburzswitzerland.ch/en/delivery_vehicles/eTrolley4_1 (Accessed 28 June 2019)

Lenz, B. and Riehle, E. (2013). Bikes for urban freight? Transportation Research Record: Journal of the Transportation Research Board, 2379, 39-45.

Living Wage Foundation (2019). The calculation. https://www.livingwage.org.uk/calculation (Accessed 28 June 2019)

Low Carbon Vehicle Partnership (2017). Emissions testing of urban delivery commercial vehicles.

https://www.lowcvp.org.uk/assets/reports/LowCVP\%20TfL\%202016\%20Test\%20Programm e\%20Final\%20Report.pdf (Accessed 28 June 2019)

Luxen, D. and Vetter, C. (2011). Real-time routing with OpenStreetMap data. In: Proceedings of the 19th ACM SIGSPATIAL International Conference on Advances in Geographic Information Systems - GIS '11, 513-516. DOI: 10.1145/2093973.2094062

Maes, J. and Vanelslander, T. (2012). The use of bicycle messengers in the logistics chain, concepts further revised. Procedia - Social and Behavioral Sciences 39, 409-423.

Mayor of London and Transport for London (2018). TLRN performance report, Quarter 2, 2017/18. http:/content.tfl.gov.uk/street-performance-report-quarter2-2017-2018.pdf (Accessed 28 June 2019)

McKinnon, A. (2016) Crowdshipping: A communal approach to reducing urban traffic levels?, Logistics White Paper 1/2016. DOI: 10.13140/RG.2.2.20271.53925

Melo, S. and Baptista, P. (2017). Evaluating the impacts of using cargo cycles on urban logistics: integrating traffic, environmental and operational boundaries. European Transport Research Review 9, 30. 
Mintel (2019). Delivering the goods: British courier and express delivery market hit $£ 12.6$ billion in 2018, https://www.mintel.com/press-centre/retail-press-centre/delivering-thegoods-british-courier-and-express-delivery-market-hit-12-6-billion-in-2018 (Accessed 28 June 2019)

Motor Transport (2019). Annual Cost Tables. https://motortransport.co.uk/annual-cost-tables/ (Accessed 28 June 2019)

Newitts (2019). Grays GX800 Goal Keeper Holdall. https://www.newitts.com/grays-gx800goal-keeper-holdall (Accessed 28 June 2019)

Nocerino, R. Colorni, A., Lia, F. and Luè, A. (2016). E-bikes and E-scooters for smart logistics: environmental and economic sustainability in pro-E-bike Italian pilots, 6th Transport Research Arena, 18-21 April, Transportation Research Procedia, 14, 2362 - 2371.

OpenStreetMap contributors (2017). Planet dump retrieved from https://planet.osm.org (Accessed 30 November 2017)

Parcelly (2019). Parcel collection should be simple - and so is our pricing. https://parcelly.com/pricing (Accessed 28 June 2019)

Perboli, G. and Rosano, M. (2019). Parcel delivery in urban areas: Opportunities and threats for the mix of traditional and green business models. Trans. Res. C: Emerging Tech. 99, 1936.

Piecyk, M., Cherrett, T.J., Allen, J., Piotrowska, M., Clarke, S., Bates, O., Bektas, B., Friday, A., McLeod, F.N., Oakey, A., Wise, S. (2019). Using on-foot porters for last-mile parcel deliveries: results of a trial in central London. In: Conference proceedings. Transportation Research Board $98^{\text {th }}$ Annual Meeting, Washington D.C., USA.

Post \& Parcel (2019). Global shipping volume to reach 200 billion parcels by 2025. https://postandparcel.info/115274/news/global-shipping-volume-to-reach-200-billion-parcelsby-2025/ (Accessed 19 November 2019)

PRO-E-BIKE (2015). Description of PRO-E-BIKE scenario. http://www.pro-e-bike.org/wpcontent/uploads/2016/06/D-6-3-Description-of-PRO-E-BIKE-scenario-1.pdf (Accessed 28 June 2019)

Ryan, A. (2019). Ford partners with Gnewt to trial 'warehouse on wheels' delivery service https://www.commercialfleet.org/news/latest-news/2019/02/18/ford-partners-with-gnewt-totrial-warehouse-on-wheels-delivery-service (Accessed 28 June 2019)

Schier, M., Offermann, B., Weigl, J.D., Maag, T., Mayer, B., Rudolph, C., Gruber, J. (2016). Innovative two-wheeler technologies for future mobility concepts, $11^{\text {th }}$ International Conference on Ecological Vehicles and Renewable Energies, Monte Carlo, Monaco.

Schliwa, G., Armitage, R., Aziz, S., Evans, J., Rhoades, J. (2015). Sustainable city logistics - Making cargo cycles viable for urban freight transport. Research in Transportation Business \& Management 15, 50-57. 
Taylor, M., Marsh, G., Nicol, D., Broadbent, P. (2017). Good Work: The Taylor Review of Modern Working Practices, https://www.thersa.org/globalassets/pdfs/reports/good-worktaylor-review-into-modern-working-practices.pdf (Accessed 28 June 2019)

Transport for London (2019). Pay to drive in London. https://tfl.gov.uk/modes/driving/payto-drive-in-london (Accessed 28 June 2019)

University of Waterloo (2016). Concorde TSP Solver.

http://www.math.uwaterloo.ca/tsp/concorde.html (Accessed 8 January 2020)

Urban Arrow (2019). Cargo. https://www.urbanarrow.com/en/cargo (Accessed 28 June 2019)

US Postal Service (2014). Using the 'Crowd' to Deliver Packages, Issue in Focus. Office of the Inspector General, Washington DC.

https://www.uspsoig.gov/sites/default/files/document-library-

files/2015/using_the_crowd_to_deliver_packages_0.pdf (Accessed 8 January 2020)

Velove (2019). Get productive in last mile delivery! https://www.velove.se/ (Accessed 28 June 2019)

Wrighton, S. and Reiter, K. (2016). CycleLogistics - moving Europe forward!, The $9^{\text {th }}$ International Conference on City Logistics, Transportation Research Procedia, 12, 950-958. 